\title{
Decreased electrical excitability of peripheral nerves in demyelinating polyneuropathies
}

\author{
J Meulstee, A Darbas, P A van Doorn, L van Briemen, F G A van der Meché
}

\begin{abstract}
Not recognising the presence of decreased excitability may give rise to a seemingly low compound muscle action potential, which may lead erroneously to the conclusion of conduction block. To quantify decreased electrical excitability, stimulation-response curves and the current needed to achieve $90 \%$ of the maximal compound muscle action potential amplitude, $\mathbf{1 9 0 ,}$ were obtained in 17 healthy controls, eight patients with Guillain-Barré syndrome, 14 with chronic inflammatory demyelinating polyneuropathy, and 10 with hereditary motor sensory neuropathy type I. Decreased electrical excitability was found in patients with chronic inflammatory demyelinating polyneuropathy and hereditary motor sensory neuropathy type $I$, by contrast with patients with Guillain-Barré syndrome. Recognising decreased excitability prevents the false assertion of conduction block and has electrodiagnostic importance for the differential diagnosis of demyelinating polyneuropathies.
\end{abstract}

( $($ Neurol Neurosurg Psychiatry 1997;62:398-400)

Keywords: hypoexcitability; demyelinating polyneuropathy; peripheral nerves

The occurrence of lowered motor nerve conduction velocities (m-NCV) in chronic demyelinating polyneuropathies is well documented and is one of the hallmarks in the electrodiagnosis of chronic inflammatory demyelinating polyneuropathy (CIDP) and hereditary motor and sensory neuropathy type I (HMSN type I). To our knowledge this is the first explicit report on the study of decreased electrical excitability in these polyneuropathies. Failing to recognise the presence of decreased excitability may lead to inadequate (not supramaximal) stimulation. ${ }^{12}$ Proximal stimulation sites, where nerves are buried deeper, are more prone to submaximal stimulation. Hence, the seemingly lower compound muscle action potential (CMAP) at proximal stimulation would erroneously lead to the assertion of conduction block. In the present study we adapted a technique originally described by Brismar ${ }^{3}$ to quantify electrical excitability of peripheral nerves in these polyneuropathies.

\section{Patients and methods}

We studied 17 healthy controls, eight patients with Guillain-Barré syndrome within three weeks after onset of the disease, 14 with CIDP, and 10 with HMSN type I. All patients in the present study fulfilled the established clinical and electrodiagnostic criteria for Guillain-Barré syndrome, ${ }^{4} \mathrm{CIDP},{ }^{5}$ or HMSN type $\mathrm{I}^{6}{ }^{6}$ The CMAP of the abductor digiti quinti muscle was recorded after stimulation of the ulnar nerve at the wrist using standard techniques. ${ }^{7}$ Surface disk electrodes were positioned in the tendon-belly montage, such that the CMAP had a maximal (top-top) amplitude, shortest (negative) duration, and steepest initial upward (negative) deflection. The optimal stimulation site at the wrist was searched for, such that a maximal CMAP amplitude could still be elicited with the least possible stimulation current. Stimulating electrodes were firmly attached to the skin and, in addition, the subject was asked to relax the hand as much as possible, to avoid changes in the response due to shifted electrode positions.

The constant current stimulator of the myograph (Viking, Nicolet) was set to a duration of $1 \mathrm{~ms}$, because in some patients the maximal current output of $80 \mathrm{~mA}$ still would not result in supramaximal stimulation at $0.3 \mathrm{~ms}$. Stimulus current was increased with small increments and the amplitudes of the successively evoked CMAPs were measured until the supramaximal stimulation level was reached. For each subject a stimulation-response plot was constructed. These curves typically consisted of 20-30 measurements. By interpolation we determined the current needed to achieve $90 \%$ of the maximal CMAP amplitude (i90).

\section{Results}

Each individual stimulus-response curve showed a typical sigmoidal configuration. The figure shows the raw data acquired from five selected subjects belonging to each of the four categories-healthy controls, GuillainBarré syndrome, CIDP, and HMSN type I. 
Stimulus response curves for normal controls and patients with Guillain-

Barré syndrome (GBS), HMSN I, or CIDP.
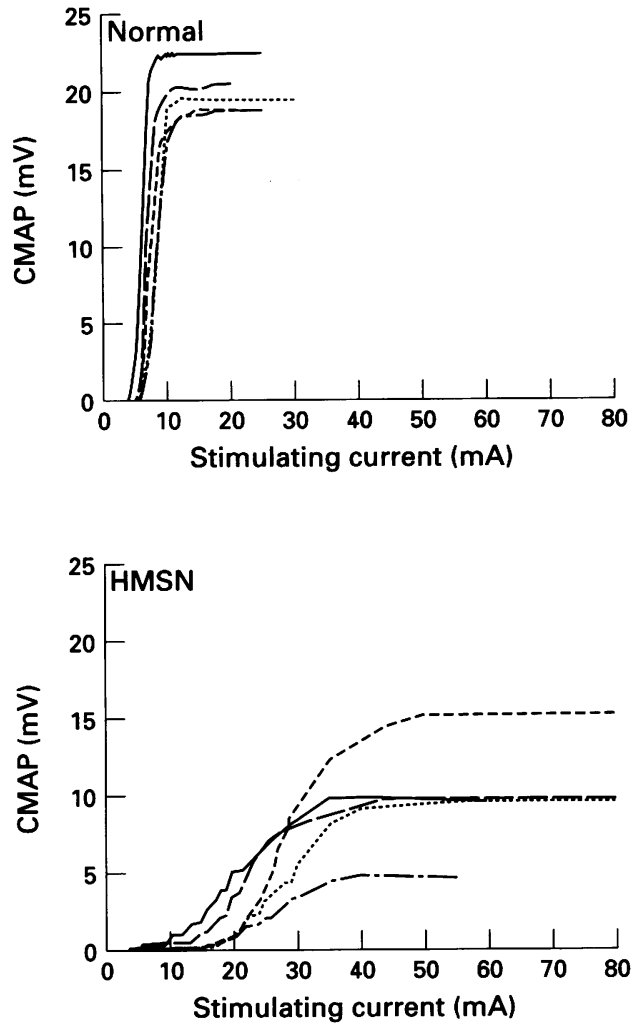

Qualitatively, such a curve can be characterised by its maximal amplitude and its slope. Curves for healthy controls and patients with Guillain-Barré syndrome show about the same slope, however with a different $\mathrm{CMAP}_{\max }$. By contrast, as is obvious from the figure curves for patients with CIDP and HMSN type I that have a much less steep slope. Hence, three different groups emerge: (1) normal subjects, (2) patients with Guillain-Barré syndrome, and (3) patients with CIDP and HMSN type I. Comparison of the i90 showed a highly significant difference between normal subjects and patients with Guillain-Barré syndrome versus patients with CIDP and HMSN (analysis of variance (ANOVA), $P<0.00$; table). This underlines the pathological decreased electrical excitability in CIDP and HMSN, whereas the excitability in Guillain-Barré syndrome lies within normal limits. The $\mathrm{CMAP}_{\max }$ showed a significant difference between normal subjects and patients with Guillain-Barré syndrome, CIDP, or HMSN (ANOVA, p < 0.001; table). We found no association of decreased excitability with age, duration of illness, motor nerve conduction slowing, distal motor latency, or conduction block in the ulnar nerve.
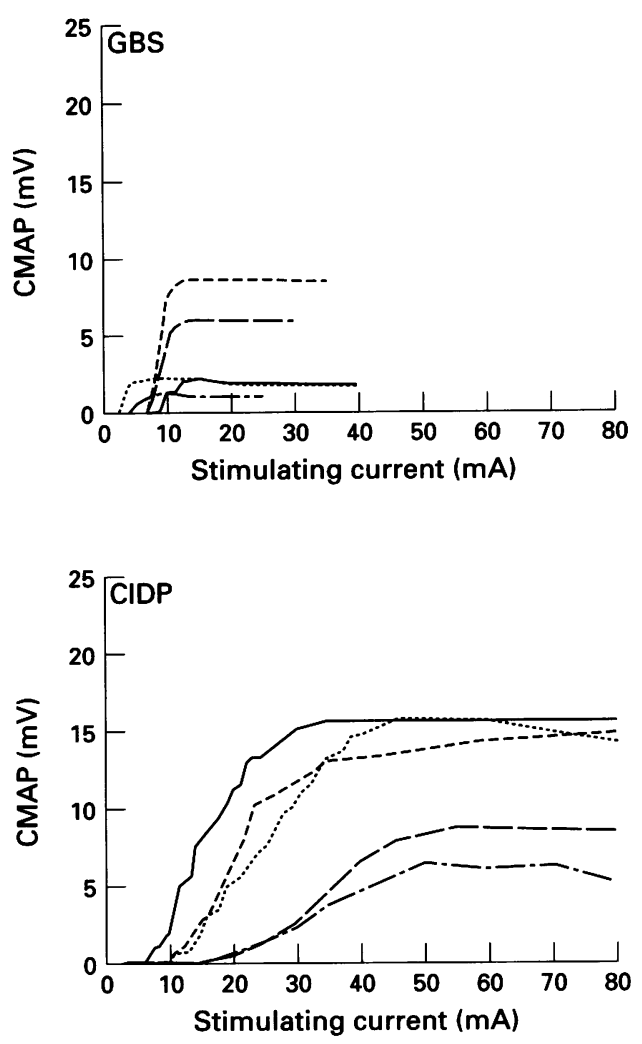

\section{Discussion}

The threshold current for generation of action potentials in individual motor nerve fibres is among other variables, dependent on axon diameter. Therefore, if a motor nerve is stimulated electrically with successively increasing stimulus strengths, an increasing number of motor units will be recruited, resulting in an increasing CMAP amplitude. ${ }^{8}$ In a normal peripheral nerve the thresholds of individual fibres lie relatively close together, which is reflected by the steep slope of the stimulusresponse curve in normal nerves (figure). As is obvious from the figure, in chronic demyelinating polyneuropathies some motor fibres have considerably higher thresholds for the generation of an action potential. The phenomenon of decreased electrical excitability is easily quantifiable by determining the i90, which is significantly higher in patients with CIDP and HMSN compared with normal subjects and patients with Guillain-Barré syndrome. On the other hand $\mathrm{CMAP}_{\max }$ is decreased in all patients, which confirms the diagnostic relevance of reduction of CMAP amplitude in these demyelinating polyneuropathies. Therefore, it seems that chronic demyelination leads to decreased electrical

Comparison of CMAP and 90 in healthy controls and patients with Guillain-Barré syndrome, CIDP, or HMSN type I

\begin{tabular}{|c|c|c|c|c|c|c|c|c|c|}
\hline & \multirow[b]{2}{*}{$n$} & \multicolumn{4}{|l|}{$C M A P$} & \multicolumn{4}{|l|}{$i 90$} \\
\hline & & Mean (SD) & $\begin{array}{l}\text { Guillain- } \\
\text { Barré } \\
\text { syndrome }\end{array}$ & $C I D P$ & HMSN I & Mean (SD) & $\begin{array}{l}\text { Guillain- } \\
\text { Barré } \\
\text { syndrome }\end{array}$ & $C I D P$ & $H M S N I$ \\
\hline $\begin{array}{l}\text { Normal controls } \\
\text { Guillain-Barré syndrome } \\
\text { CIDP } \\
\text { HMSN I }\end{array}$ & $\begin{array}{r}17 \\
8 \\
14 \\
10\end{array}$ & $\begin{array}{r}18 \cdot 6(4 \cdot 0) \\
4 \cdot 7(4 \cdot 6) \\
9 \cdot 9(4 \cdot 4) \\
8 \cdot 3(3 \cdot 1)\end{array}$ & $\begin{array}{l}P<0.001 \\
- \\
-\end{array}$ & $\begin{array}{l}P<0.001 \\
\text { NS } \\
-\end{array}$ & $\begin{array}{l}P<0.001 \\
\text { NS } \\
\text { NS } \\
-\end{array}$ & $\begin{array}{c}8.7(2 \cdot 3) \\
10 \cdot 1(4 \cdot 0) \\
39.9(19 \cdot 2) \\
36 \cdot 8(15 \cdot 0)\end{array}$ & $\begin{array}{l}\text { NS } \\
- \\
-\end{array}$ & $\begin{array}{l}\mathrm{P}<0.001 \\
\mathrm{P}<0.001 \\
-\end{array}$ & $\begin{array}{l}\mathrm{P}<0.001 \\
\mathrm{P}<0.001 \\
\mathrm{NS} \\
-\end{array}$ \\
\hline
\end{tabular}


excitability as opposed to acute demyelination.

In our patients with CIDP and HMSN type I no correlation was found between the severity of slowing of conduction and the degree of decreased electrical excitability. In addition, in one of our patients with Guillain-Barré syndrome in whom very slowed nerve conduction occurred, signs of decreased electrical excitability were absent. We found no significant correlation between the incidence of conduction block and the degree of decreased electrical excitability in these patients. Therefore, it seems that decreased electrical excitability is at least not simply dependent on the slowing of $\mathrm{m}-\mathrm{NCV}$ or the incidence of conduction block in these polyneuropathies. Decreased electrical excitability is a local phenomenon of abnormality in the nerve at the site of stimulation. In the present study, the reduction in CMAP amplitude reflects conduction block and axonal degeneration. Compared with Guillain-Barré syndrome, the contribution of axonal loss is probably much larger in chronic demyelinating polyneuropathies. The decrease in fibre diameters, as described in HMSN type $I$, is probably too small to fully explain decreased excitability. ${ }^{68}$ However, changes in the myelin, such as the formation of onion bulbs due to Schwann cell proliferation, could possibly explain the decreased excitability in this polyneuropathy by an increased input resistance. In some patients with CIDP, we have noted fluctuations in excitability over several days during plasmapheresis or immune globulin therapy. ${ }^{910}$ This may suggest a mechanism of immunological modulation of sodium channel kinetics rather than a change in the morphological changes. Hence, different mechanisms of decreased electrical excitability may play a part in these polyneuropathies. The search for a decreased electrical excitability will, apart from preventing the erroneous establishment of conduction block, assist in the differential diagnosis of demyelinating polyneuropathies.

1 Kaku DA, Parry GJ, Malamut R, Lupski JR, Garcia CA Uniform slowing of conduction velocities in CharcotMarie-Tooth polyneuropathy type I. Neurology 1993;43: 2664-7.

2 Hoogendijk JE, de Visser M, Bour LJ, Ongerboer BW. Conduction block in hereditary motor and sensory neuropathy type I [letter]. Muscle Nerve 1992;15:520-1.

3 Brismar T. Changes in electrical threshold in human peripheral neuropathy. $\mathcal{F}$ Neurol Sci 1985;68:215-23.

4 Asbury AK, Cornblath DR. Assessment of current diagnostic criteria for Guillain-Barré Syndrome. Ann Neurol 1990;27(suppl):S21-4.

5 Ad Hoc Subcommittee of the American Academy of Neurology AIDS Task Force. Research criteria for diagnosis of chronic inflammatory demyelinating polyneunosis of chronic inflammatory dem.

6 Gabreëls-Festen AAWM, Gabreëls FJM, Jennekens FGI Hereditary motor and sensory neuropathies. Present status Hereditary motor and sensory neuropathies. Present status
of types I, II and III. Clin Neurol Neurosurg 1993;95: of types

7 Meulstee J, van der Meché FGA, and the Dutch GuillainBarré Study Group. Electrodiagnostic criteria for polyneuropathy and demyelination: application in 135 patients with Guillain-Barré syndrome. $\mathcal{f}$ Neurol Neurosurg Psychiatry 1995;59:482-6.

8 Veltink PH, van Alste JA, Boom HBK. Influences of stimulation conditions on recruitment of myelinated fibres: model study. IEEE Trans Biomed Eng 1988;35:917-24.

9 Van Doorn PA, Brand A, Strengers PFW, Meulstee J, Vermeulen M. High-dose intravenous immunoglobulin treatment in chronic inflammatory demyelinating polyneuropathy: a double blind placebo-controlled cross polyneuropathy: a double blind placeb
over study. Neurology 1990;40:209-12.

10 Van der Meché FGA, Vermeulen M, Busch HFM Chronic inflammatory demyelinating polyneuropathy: Chronic inflammatory demyelinating polyneuropathy: plasmatherapy. Brain 1989;112:1563-71. 